\title{
Comparative Study of the Influence of Air Pollution on UVI at Maitri in Antarctica and New Delhi in India
}

\author{
Nandita D. Ganguly \\ Department of Physics, St. Xavier's College, Ahmedabad 380009, Gujarat, India \\ Correspondence should be addressed to Nandita D. Ganguly, ganguly.nandita@gmail.com
}

Received 18 July 2011; Accepted 5 September 2011

Academic Editor: D. Moreira

Copyright () 2012 Nandita D. Ganguly. This is an open access article distributed under the Creative Commons Attribution License, which permits unrestricted use, distribution, and reproduction in any medium, provided the original work is properly cited.

The influence of air pollution on the erythemal ultraviolet irradiance (UVI) reaching the earth's surface has been investigated at the Indian Antarctic station Maitri and compared with that at New Delhi, the capital of India, over a period of three years from 2005 to 2007. Total ozone column (TOC), surface ozone, $\mathrm{NO}_{2}$ column, middle tropospheric $\mathrm{SO}_{2}$ column, and BrO column are observed to exhibit a deceasing trend at Maitri, having a clean and pristine environment, while UVI and aerosol optical depth at $500 \mathrm{~nm}$ exhibit an increasing trend. This negative correlation suggests that $\mathrm{O}_{3}, \mathrm{NO}_{2}, \mathrm{SO}_{2}$, and $\mathrm{BrO}$ act as filters against erythemal ultraviolet irradiance reaching the earth's surface, while the aerosols, which are present in the atmosphere of Maitri, may not be either very effective in filtering out the UVI reaching the earth's surface or may not be large enough to produce measurable effects on UVI. TOC and BrO column are observed to exhibit a deceasing trend at New Delhi, having comparatively higher levels of pollution, while UVI, $\mathrm{NO}_{2}$ column, middle tropospheric $\mathrm{SO}_{2}$ column, surface ozone, and aerosol optical depth at $500 \mathrm{~nm}$ exhibit an increasing trend. This suggests that TOC and $\mathrm{BrO}$ act as filters against UVI, while $\mathrm{NO}_{2}$, surface ozone, $\mathrm{SO}_{2}$, and aerosols in the atmosphere of New Delhi may not be large enough to produce measurable effects on UVI.

\section{Introduction}

The Indian Antarctic research station Maitri $\left(70.77^{\circ} \mathrm{S}\right.$, $11.73^{\circ} \mathrm{E}$ ) is located in the coastal area of Queen Maud Land on a rocky area and is devoid of snow throughout the year [1]. It is located at the edge of the Antarctic continent and hence experiences wind from both ocean and inland. This altering air mass has an important effect on the level of air pollution and aerosols [2]. New Delhi $\left(28.38^{\circ} \mathrm{N}, 77.17^{\circ} \mathrm{E}\right)$, the capital of India, is a densely populated city and has high levels of pollution. The erythemal UV irradiance (UVI) is an estimation of the UV levels that are important for the effects on the human skin and is measured in terms of $\mathrm{mW} / \mathrm{m}^{2}$. It is a measure for the amount of UV radiation for clear-sky conditions when the Sun is in the zenith. Of the total erythemal UV irradiance, $17 \%$ is UV-A, $83 \%$ is UV-B. Study of the influence of photochemical air pollution on the UVI reaching the earth's surface at the Indian Antarctic station Maitri has special significance, because Maitri is believed to have a clean and pristine environment in absence of commercialism and industrial development. Therefore the atmosphere of
Maitri is influenced only by the long-range transport of particles and gaseous pollutants from other parts of the world. On the other hand, the atmosphere of New Delhi is influenced by in situ production of gaseous pollutants and aerosols apart from long-range transport from far off regions.

Tropospheric absorbers of UV radiation include ozone, sulfur dioxide, nitrogen oxides, bromine and chlorine compounds, hypobromous acid, and the oxygen dimer. In addition, many organic species also absorb UV radiation [36 ]. However, the presence of most of these substances in the troposphere is usually not large enough to produce measurable effects on surface UV, except near the sources of emission in polluted areas [7]. Bruhl and Crutzen [8] suggested that tropospheric ozone acts as a filter against solar UV radiation. This hypothesis was supported by Cartalis et al. [9], who observed that presence of boundary layer ozone results in a decrease in solar UV radiation at the ground, with the simultaneous presence of cloudiness, boundary layer aerosols, nonmethane hydrocarbons and nitrogen oxides $\left(\mathrm{NO}_{x}\right)$ in large amounts further intensifying this effect. Surface elevation and reflectivity also influences the amount 
of UVI reaching the earth's surface. The study of Varotsos et al. [10] further supported the hypothesis of the filtering of solar UV radiation by photochemical air pollution. Bernhard et al. [11] reported that most cloud cover on the high Antarctic Plateau is optically thin, and $71 \%$ of clouds had optical depth less than 1 . As a result, due to small optical depth and high surface albedo, the average cloud attenuation of UV radiation was only 5\%. Apart from this, greenhouse gases contribute to cooling of the stratosphere, thus affecting the ozone chemistry, and warming at the surface, which, in turn, leads to changes in many variables that are capable of modifying the UV radiation at the surface [7]. Efstathiou et al. [12] reported that increased presence of $\mathrm{NO}_{2}$ in the lower troposphere may result in a decrease in the UV-B on the ground.

\section{Data and Analysis}

The total ozone column (TOC) data for Maitri and New Delhi having a spatial resolution of $1.0^{\circ}$ (Lat) $\times 1.25^{\circ}$ (Lon) has been obtained from earth probe total ozone mapping spectrometer (EP-TOMS) and ozone monitoring instrument (OMI). The surface ozone data has been obtained from India Meteorological Department (IMD). UVI and Bromine mono-oxide $(\mathrm{BrO})$ data from SCIAMACHY instrument has been obtained from the Tropospheric Emission Monitoring Internet Service (Temis; website http://www.temis.nl/). Monthly mean Aerosol optical depth (AOD) at $550 \mathrm{~nm}$ having a spatial resolution of $1.0^{\circ}$ (Lat) $\times 1^{\circ}$ (Lon) was obtained from moderate resolution imaging spectroradiometer (MODIS). Nitrogen dioxide $\left(\mathrm{NO}_{2}\right)$ and Sulphur dioxide $\left(\mathrm{SO}_{2}\right)$ column amount were obtained from OMI/Aura.

The TOC, surface ozone, UVI, $\mathrm{NO}_{2}, \mathrm{SO}_{2}$, and $\mathrm{BrO}$ data for Maitri and New Delhi were obtained for all available days during the period from 2005 to 2007. They were then averaged on a monthly basis for the entire period of study to determine the trend of variation (Figures 1 and 2).

\section{Results and Discussion}

As observed from Figure 1, UVI at Maitri exhibits an increasing trend of $4.97 \%$ during the period from 2005 to 2007 . The possible causes for this increase have been investigated over this pristine site, to determine the influence of air pollution, which is thereafter compared with the results obtained for New Delhi in India, having comparatively higher levels of pollution.

TOC and surface ozone at Maitri exhibit a decreasing trend of $1.63 \%$ and $0.89 \%$ during this period. The inverse correlation between ozone and UVI supports the hypothesis of Bruhl and Crutzen [8] that tropospheric ozone may act as a filter against solar UV radiation.

$\mathrm{NO}_{2}$, middle tropospheric $\mathrm{SO}_{2}$ column and $\mathrm{BrO}$ exhibit a decreasing trend of $1.543 \%, 3.24 \%$, and $0.038 \%$, respectively, during this period. This indicates that apart from ozone, $\mathrm{NO}_{2}, \mathrm{SO}_{2}$, and BrO may also act as filters against solar UV radiation.

AOD is a measure of the attenuation of direct solar radiation that occurs while passing through the atmosphere containing aerosols. It depends upon the amount, size distribution, and chemical composition of aerosols [2]. Gadhavi and Jayaraman [2] have observed the presence of nucleationmode particles at Maitri, which are produced mainly in situ within the atmosphere by gas-to-particle conversion mechanism from precursor gases such as oxides of sulphur and nitrogen. They have also observed the presence of particles, which are of local and natural origin and composed mainly of sea-salt particles from the ocean and dust debris from the underlying land. It is observed in this study that AOD values at Maitri are low (0.025-0.275) and exhibit an increasing trend of $24 \%$ (Figure 1). The positive correlation observed between AOD and UVI and low values of AOD at Maitri implies that aerosols, which are present in the atmosphere of Maitri, may not be either very effective in filtering out the UVI reaching the earth's surface or may not be large enough to produce measurable effects on UVI.

As observed from Figure 2, UVI at New Delhi exhibits an increasing trend of $0.184 \%$ during the period from 2005 to 2007, while TOC exhibits a decreasing trend of $0.17 \%$ during this period. According to the estimates of Dasgupta and Bhaumik [13], it is likely that $10 \%$ decrease in ozone will lead to $20 \%$ increase in UV irradiance. However, the observed increase in UVI is less than that estimated by Dasgupta and Bhaumik [13], which may be due to the additional filtering of UVI by gaseous pollutants and aerosols.

$\mathrm{BrO}$ exhibits a decreasing trend of $0.082 \%$ during this period. This indicates that apart from ozone, $\mathrm{BrO}$ may also act as a filter against solar UV radiation.

$\mathrm{NO}_{2}$, middle tropospheric $\mathrm{SO}_{2}$ column and Surface ozone at New Delhi exhibit an increasing trend of $1.7 \%$, $3.75 \%$, and $6.36 \%$, respectively (Figure 2 ). Due to reduced $\mathrm{OMI}$ sensitivity to $\mathrm{SO}_{2}$ in the planetary boundary layer, this parameter has large uncertainty and it retrieves negative values at New Delhi. This suggests that TOC and $\mathrm{BrO}$ act as filters against UVI, but the concentration of $\mathrm{NO}_{2}$, middle tropospheric $\mathrm{SO}_{2}$, and surface ozone in the atmosphere of New Delhi may not be large enough to produce measurable effects on UVI. AOD values at New Delhi are high (0.2841.169 ) and exhibit an increasing trend of $2.35 \%$ (Figure 2 ). In spite of high AOD, the positive correlation observed between UVI and AOD suggests that the aerosols, which are present in the atmosphere of New Delhi may not be either very effective in filtering out the UVI reaching the earth's surface or may not be large enough to produce measurable effects on UVI.

\section{Conclusions}

This paper supports the well-established fact that TOC acts as a major filter against solar UV radiation. It is further observed that surface ozone, $\mathrm{NO}_{2}$, middle tropospheric $\mathrm{SO}_{2}$ and $\mathrm{BrO}$ also filter UV radiation, while aerosols found in the atmosphere of Maitri may not be either very effective in filtering out the UVI reaching the earth's surface or may not be large enough to produce measurable effects on UVI. BrO column exhibits a deceasing trend, while UVI, $\mathrm{NO}_{2}$, surface ozone, middle tropospheric $\mathrm{SO}_{2}$, and aerosol optical depth at $500 \mathrm{~nm}$ exhibit an increasing trend at New Delhi, having 


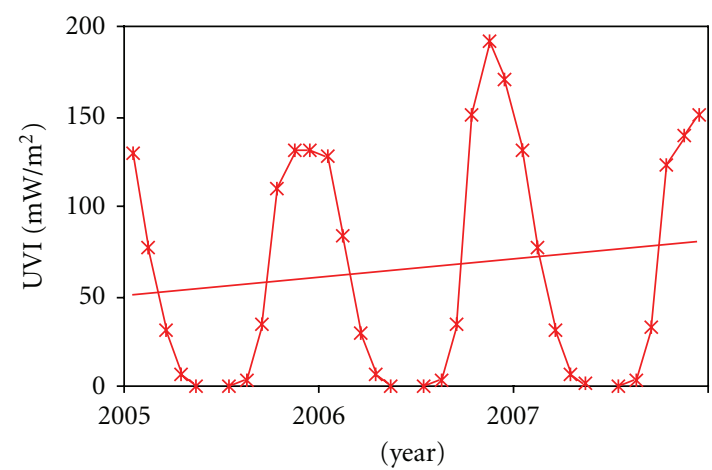

(a)

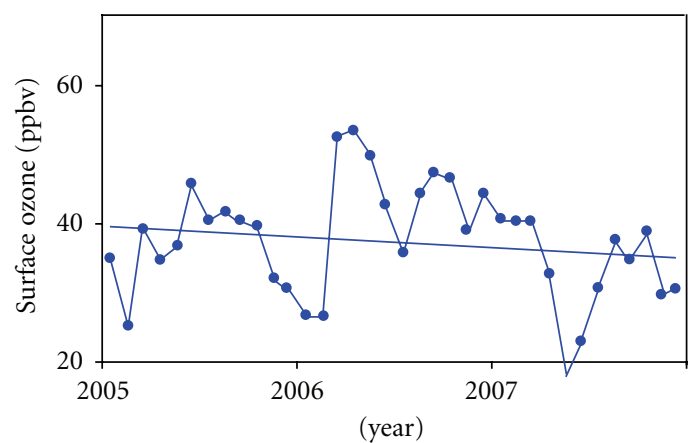

(c)

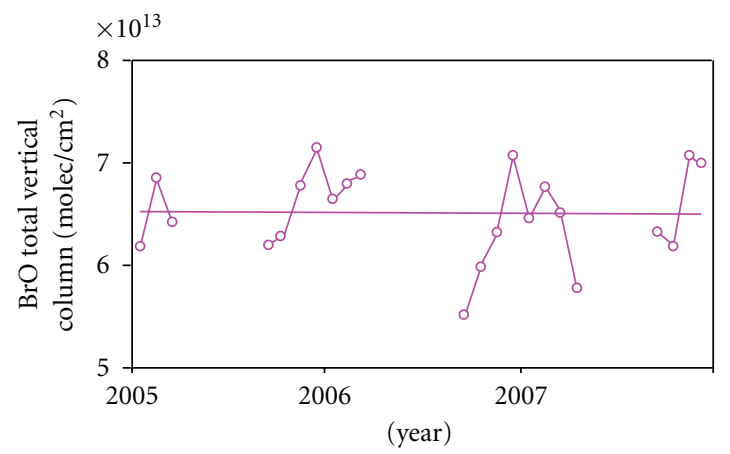

(e)

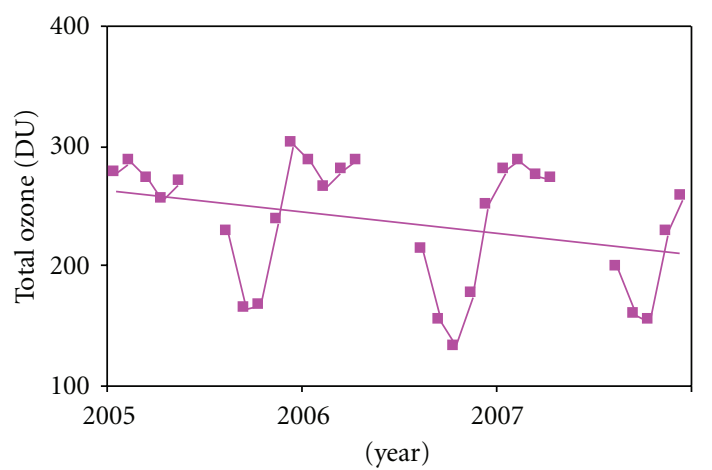

(b)

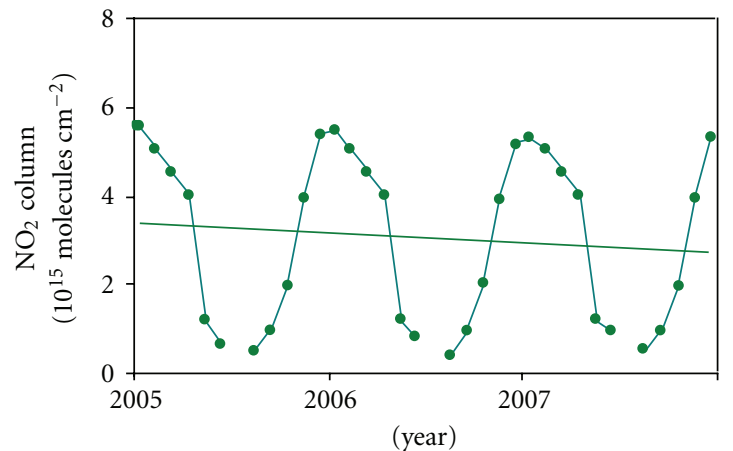

(d)

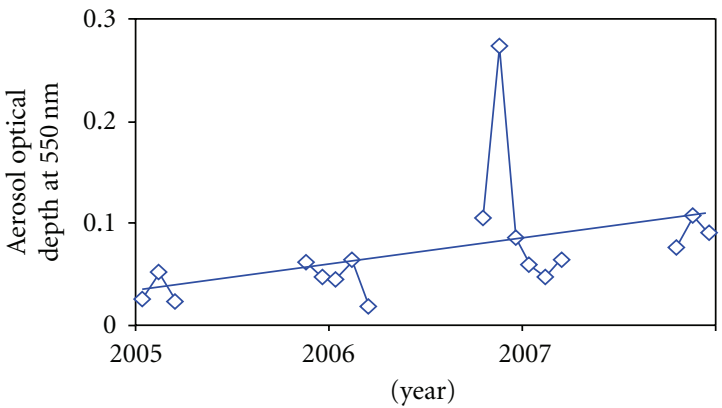

(f)

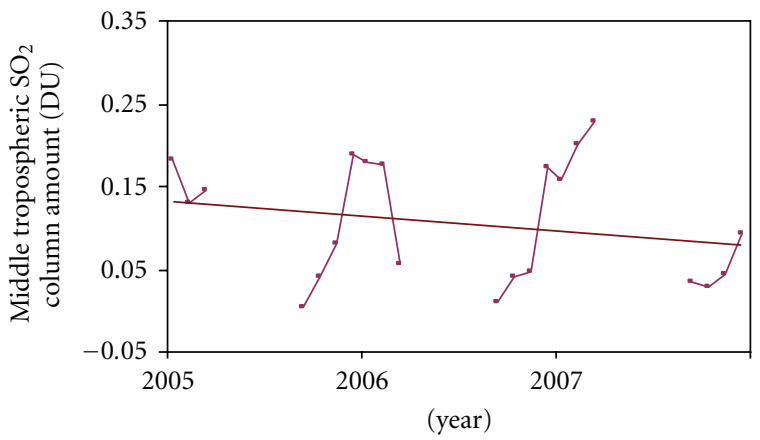

(g)

Figure 1: Comparison of the trend of UVI $\left(\mathrm{mW} \cdot \mathrm{m}^{-2} \cdot \mathrm{Yr}^{-1}\right)$ with TOC $\left(\mathrm{DU} \cdot \mathrm{Yr}^{-1}\right)$, surface ozone $\left(\mathrm{ppbv} \cdot \mathrm{Yr}^{-1}\right), \mathrm{NO}_{2} \mathrm{column}\left(10^{15}\right.$ molecules $\left.\cdot \mathrm{cm}^{-2} \cdot \mathrm{Yr}^{-1}\right), \mathrm{BrO}$ vertical column density $\left(\mathrm{molec} / \mathrm{cm}^{2}\right)$, aerosol optical depth at $550 \mathrm{~nm}$, and middle tropospheric $\mathrm{SO}_{2}$ column at Maitri during the period from 2005-2007. 


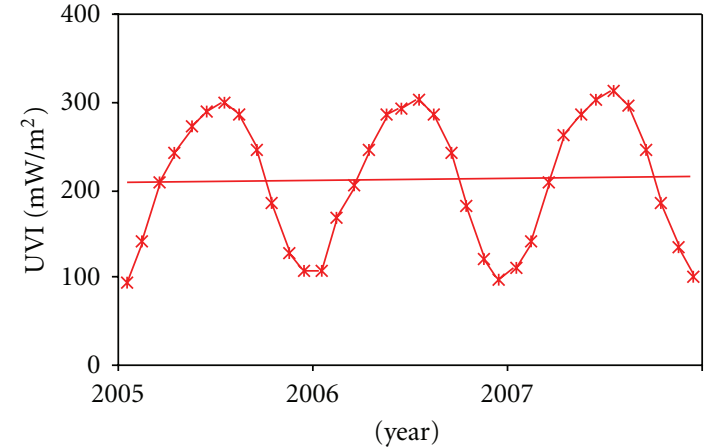

(a)

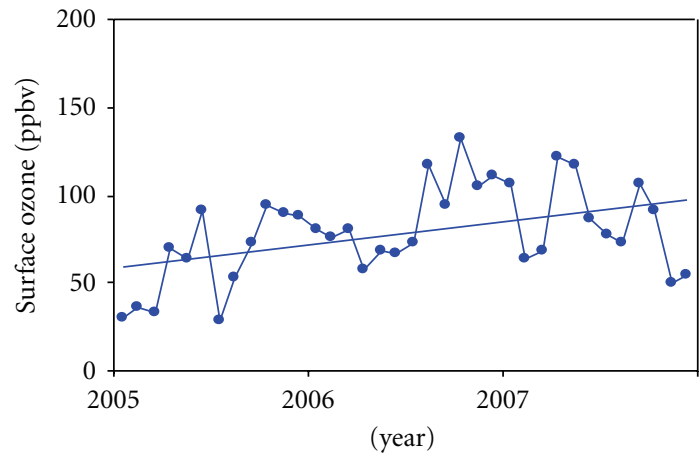

(c)

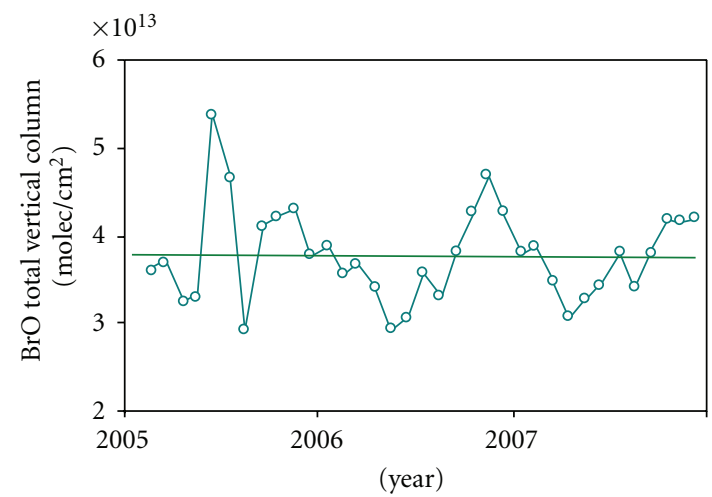

(e)

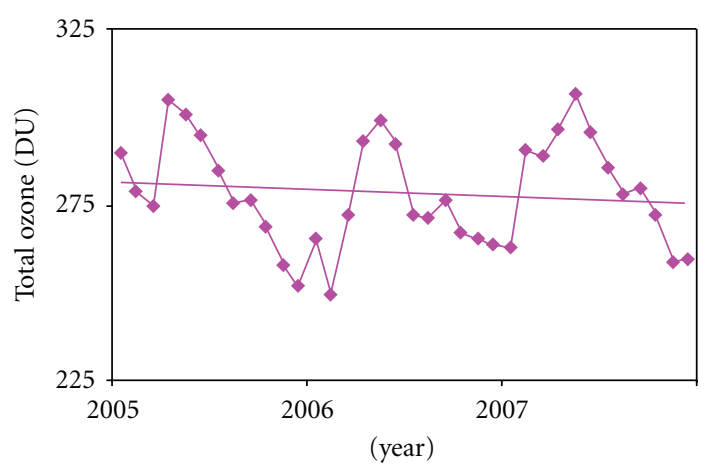

(b)

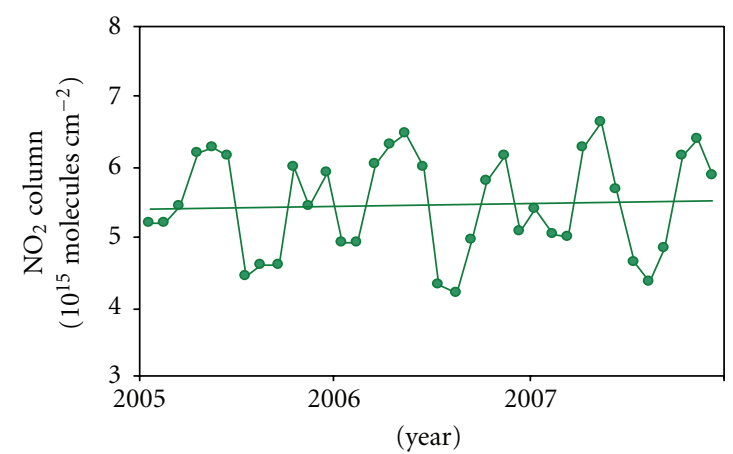

(d)

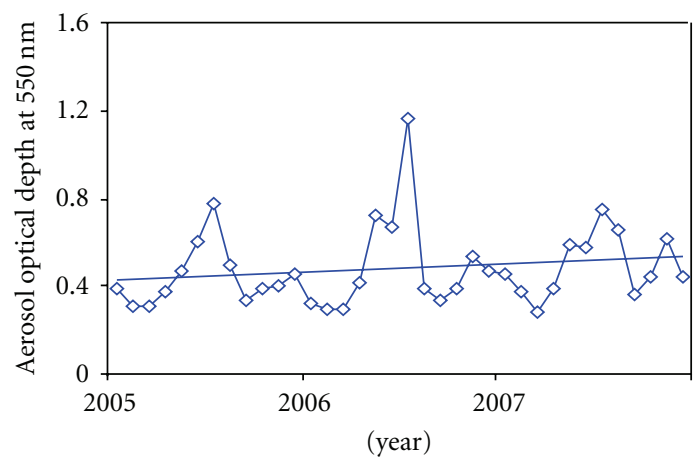

(f)

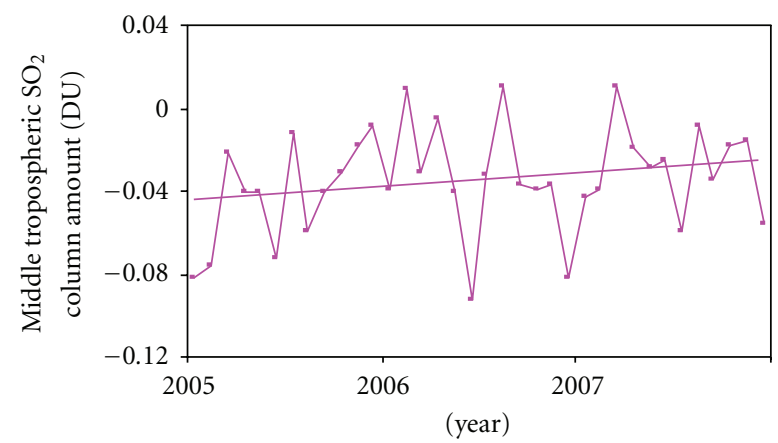

(g)

FIgure 2: Comparison of the trend of UVI $\left(\mathrm{mW} \cdot \mathrm{m}^{-2} \cdot \mathrm{Yr}^{-1}\right)$ with $\mathrm{TOC}\left(\mathrm{DU} \cdot \mathrm{Yr}^{-1}\right)$, surface ozone $\left(\mathrm{ppbv} \cdot \mathrm{Yr}^{-1}\right), \mathrm{NO}_{2} \mathrm{column}\left(10^{15}\right.$ molecules $\left.\cdot \mathrm{cm}^{-2} \cdot \mathrm{Yr}^{-1}\right), \mathrm{BrO}$ vertical column density $\left(\mathrm{molec} / \mathrm{cm}^{2}\right)$, aerosol optical depth at $550 \mathrm{~nm}$, and middle tropospheric $\mathrm{SO}_{2}$ column at New Delhi during the period from 2005-2007. 
comparatively higher levels of pollution. This suggests that TOC and $\mathrm{BrO}$ act as filters against UVI, but surface ozone, middle tropospheric $\mathrm{SO}_{2}$, and $\mathrm{NO}_{2}$ in the atmosphere of New Delhi may not be large enough to produce measurable effects on UVI. The aerosols, which are present in the atmosphere of New Delhi may not be either very effective in filtering out the UVI reaching the earth's surface or may not be large enough to produce measurable effects on UVI.

However, since most of the measurements involve remotely sensed satellite data over a short period of time, extensive in situ measurements are necessary on a long-term basis to conclude strongly on the influence of photochemical pollution on the erythemal ultraviolet irradiance reaching the earth's surface.

\section{Acknowledgments}

The monthly mean TOC data has been obtained from EP TOMS and OMI. The surface ozone data has been obtained from IMD. UVI data from SCIAMACHY instrument has been obtained from the website http:/wwwtemis.nl/. Monthly mean Level-3 Aerosol optical depth at $550 \mathrm{~nm}$ was obtained from MODIS. UV aerosol index and, $\mathrm{NO}_{2}$ and $\mathrm{SO}_{2}$ column amount were obtained from OMI/Aura. Analyses and visualizations used in this paper were produced with the Giovanni online data system developed and maintained by the NASA GES DISC.

\section{References}

[1] B. B. Bhattacharya, "Schumacher Oasis: environment, history and the Indian Station Maitri," Scientific Report of the Fourth Indian Expedition, Technical Publication 4, pp. 171-186, Department of Ocean Development, New Delhi, India, 1987.

[2] H. Gadhavi and A. Jayaraman, "Aerosol characteristics and aerosol radiative forcing over Maitri, Antarctica," Current Science, vol. 86, no. 2, pp. 296-304, 2004.

[3] R. Atkinson, D. L. Baulch, R. A. Cox et al., "Evaluated kinetic, photochemical and heterogeneous data for atmospheric chemistry: supplement V: IUPAC subcommittee on gas kinetic data evaluation for atmospheric chemistry," Journal of Physical and Chemical Reference Data, vol. 26, no. 3, pp. 521-784, 1997.

[4] M. Z. Jacobson, "Isolating nitrated and aromatic aerosols and nitrated aromatic gases as sources of ultraviolet light absorption," Journal of Geophysical Research D, vol. 104, no. 3, pp. 3527-3542, 1999.

[5] S. P. Sander, R. R. Friedl, D. M. Golden et al., "Chemical kinetics and photochemical data for use in atmospheric studies: evaluation number 14," Tech. Rep. 02-25, Jet Propulsion Laboratory, Pasadena, Calif, USA, 2003.

[6] C. E. L. Myhre and C. J. Nielsen, "Optical properties in the UV and visible spectral region of organic acids relevant to tropospheric aerosols," Atmospheric Chemistry and Physics, vol. 4, no. 7, pp. 1759-1769, 2004.

[7] Scientific Assessment of Ozone Depletion, "Surface ultraviolet radiation: past, present, and future," 2007, http://ozone.unep .org/Assessment_Panels/SAP/Scientific_Assessment_2006/09Chapter_7.pdf.

[8] C. Bruhl and P. S. Crutzen, "On the disproportionate role of tropospheric ozone as a filter against solar UV-B radiation," Geophysical Research Letters, vol. 16, no. 7, pp. 703-706, 1989.
[9] C. Cartalis, C. Varotsos, H. Feidas, and A. Katsambas, "The impact of air pollution in an urban area on the amount of solar ultraviolet radiation at the surface," Toxicological \& Environmental Chemistry, vol. 36, no. 3, pp. 195-203, 1992.

[10] C. A. Varotsos, G. J. Chronopoulos, S. Katsikis, and N. K. Sakellariou, "Further evidence of the role of air pollution on solar ultraviolet radiation reaching the ground," International Journal of Remote Sensing, vol. 16, no. 10, pp. 1883-1886, 1995.

[11] G. Bernhard, C. R. Booth, and J. C. Ehramjian, "Version 2 data of the national science foundation's ultraviolet radiation monitoring network: South Pole," Journal of Geophysical Research D, vol. 109, no. 21, Article ID D21207, 18 pages, 2004.

[12] M. N. Efstathiou, H. Feretis, C. Tzanis, and J. Christodoulakis, "Observed association between air pollution and the biologically effective solar ultraviolet irradiance," International Journal of Remote Sensing, vol. 26, no. 16, pp. 3487-3495, 2005.

[13] R. Dasgupta and D. K. Bhaumik, "Upper and Lower tolerance limits of atmospheric ozone level and extreme value distribution," Indian Journal of Statistics, vol. 57, pp. 182-199, 1995. 

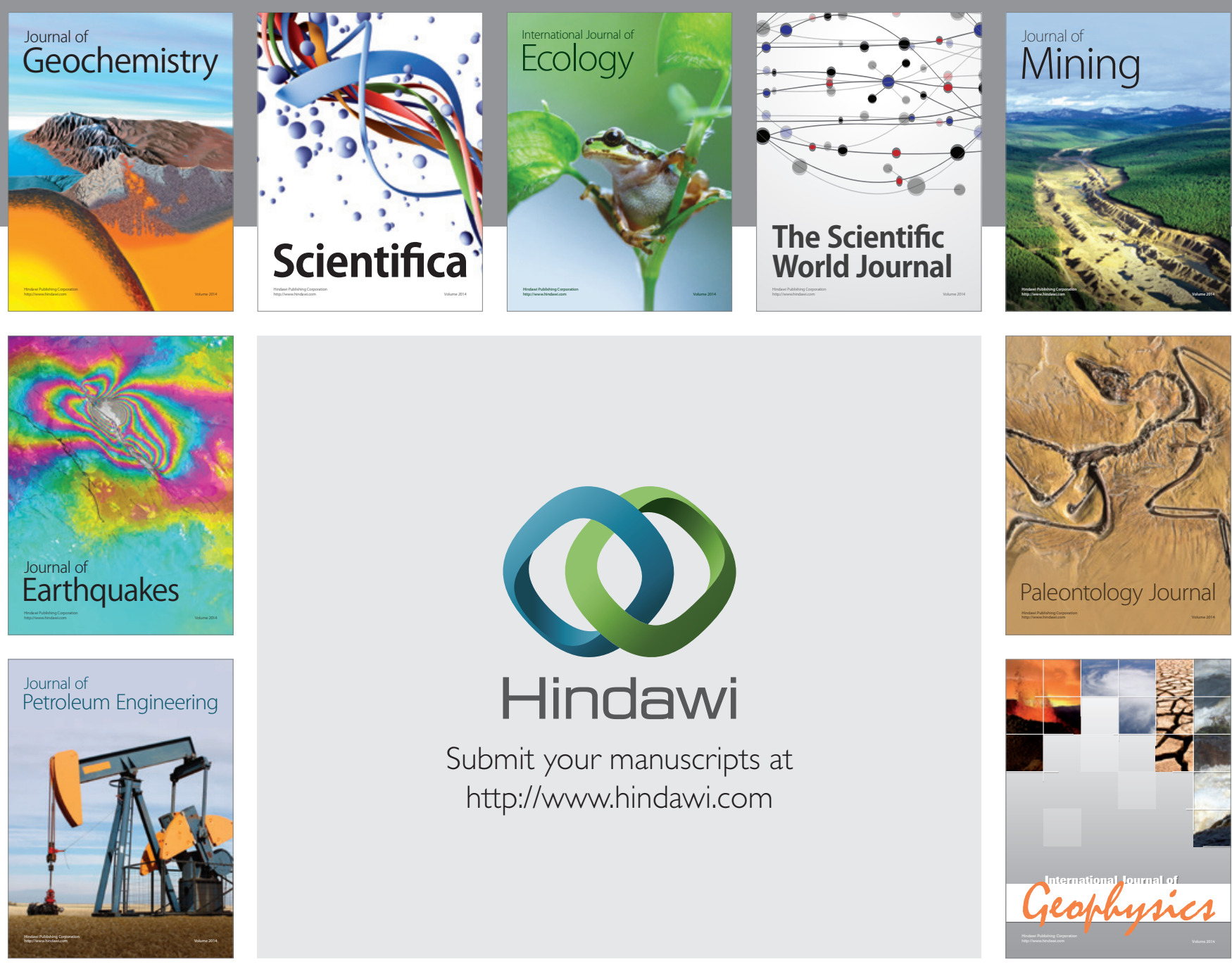

Submit your manuscripts at

http://www.hindawi.com
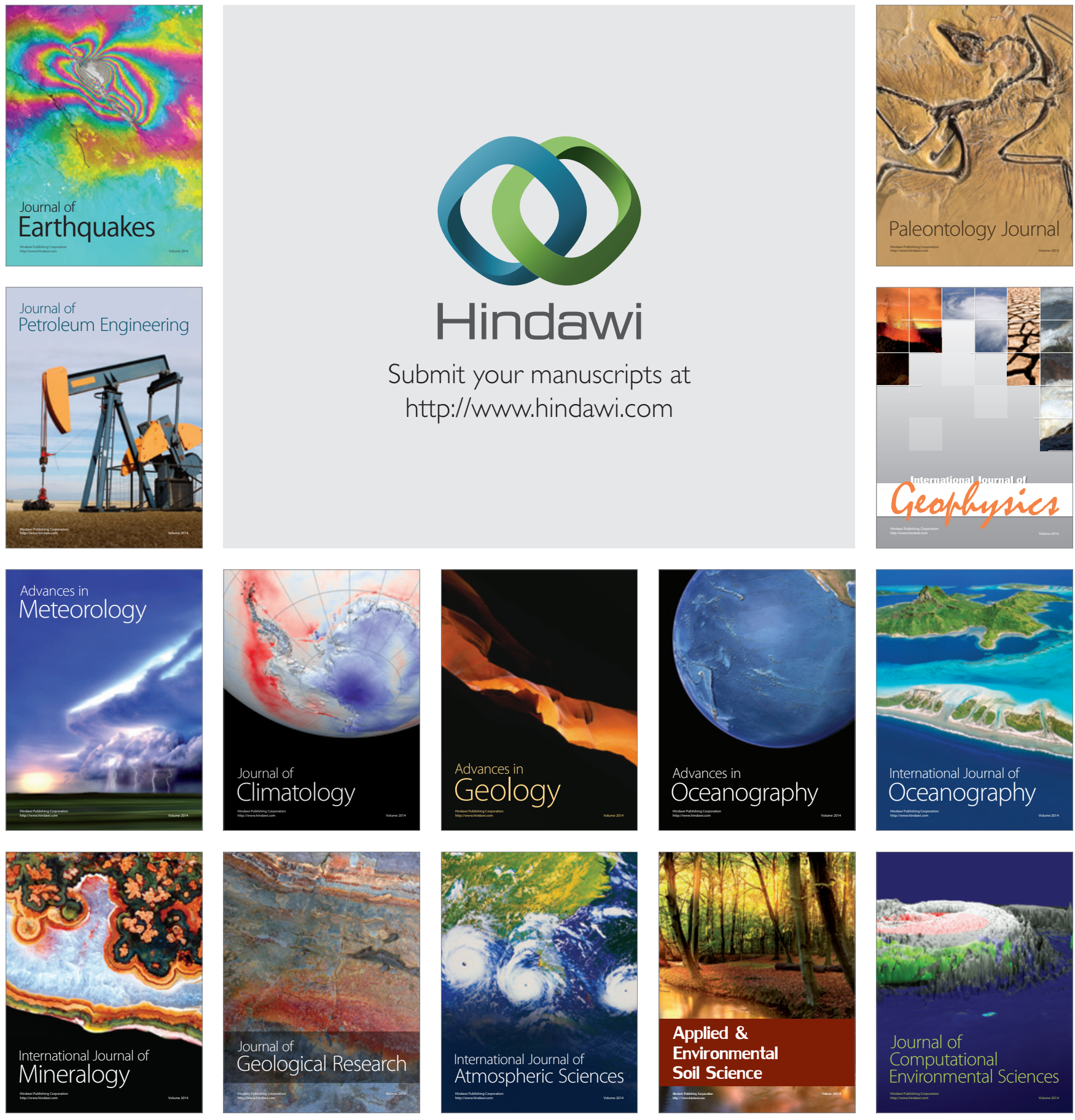